\section{In Memoriam. Dr. Luis Arturo Pérez Tamayo}

\author{
In Memoriam. Luis Arturo Pérez Tamayo, MD
}

Dr. Arturo Silva-Jiménez*

Citar como: Silva-Jiménez A. In Memoriam. Dr. Luis Arturo Pérez Tamayo. Rev Mex Anestesiol. 2022; 45 (2): 147. https://dx.doi.org/10.35366/103893

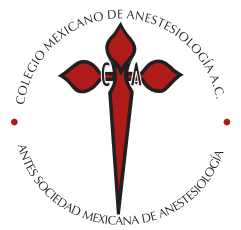

$$
\begin{aligned}
& \text { * Médico Anestesiólogo. Egresado } \\
& \text { del Centro Médico Nacional La Raza. } \\
& \text { Jubilado del IMSS. Jefe de Servicio en } \\
& \text { el Hospital Central Norte de Petróleos } \\
& \text { Mexicanos. Director Médico en el } \\
& \text { Hospital General Ciudad Pemex, Tabasco. } \\
& \text { Expresidente del Colegio Mexicano de } \\
& \text { Anestesiología, A.C. Profesor Titular del } \\
& \text { Curso de Anestesiología ante la UNAM. } \\
& \text { Correspondencia: } \\
& \text { Dr. Arturo Silva-Jiménez } \\
& \text { E-mail: dr.silvaja@gmail.com }
\end{aligned}
$$

$\mathrm{E}^{\mathrm{s}, \mathrm{n}}$ 1 Dr. Pérez Tamayo, Médico Anestesiólogo, nació en la Ciudad de México el 10 de noviembre de 1930. Realizó sus estudios y adquirió experiencia en el área académica y laboral en diversas universidades y hospitales de los Estados Unidos en los años 1950 y 1960; a su regreso a México, ocupó las Jefaturas del Departamento de Anestesiología en el Hospital de Gineco-Obstetricia No. 3 y posteriormente en el Hospital de Especialidades del Centro Médico «La Raza» en el Instituto Mexicano del Seguro Social.

Tuvo el cargo de profesor Titular del Curso para la Especialización en Anestesiología ante la Universidad Nacional Autónoma de México a partir del año 1966 hasta su jubilación laboral en 1990. Fue profesor de muchas generaciones de médicos graduados en la Especialidad de Anestesiología, formando más de mil médicos anestesiólogos para toda la República Mexicana; tengo el orgullo de haber sido uno de sus alumnos.

Profesor Académico en la Academia Nacional de Medicina de México, desempeñó diversos cargos administrativos, en la

Figura 1:

Dr. Luis Arturo Pérez Tamayo.

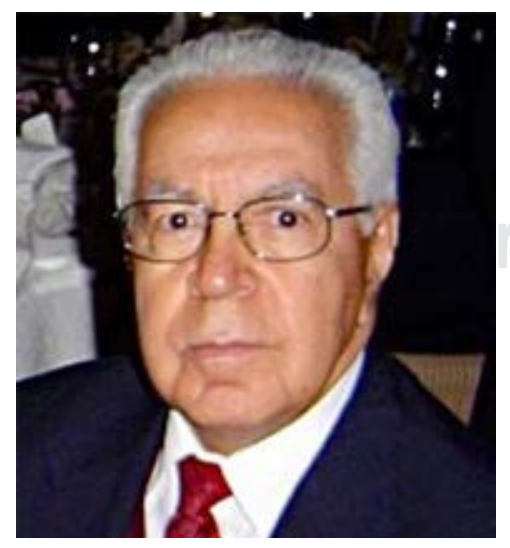

División de Estudios de postgrado de la Facultad de Medicina de la UNAM, en el Congreso Mundial de Anestesiología en 1972, en la Federación de Sociedades de Anestesiología de la República Mexicana. Se dedicó en cuerpo y alma a varias áreas administrativas, presidente del Consejo Mexicano de Anestesiología, certificó a más de 5,500 médicos anestesiólogos. Al fallecer su esposa, continúa su trabajo en el Consejo Mexicano de Anestesiología y mantiene un contacto íntimo con su familia (su hijo el Ing. Luis Pérez) y una relación muy estrecha con amigos, con sus alumnos con quienes compartían ratos de esparcimiento, vivencias y anécdotas, siempre interesado en el prójimo, aportando consejos saludables.

Hace algunos meses, don Luis presentó diversas enfermedades que limitaron sus actividades, necesitando cuidados y compañía las 24 horas del día. Por desgracia, su estado físico se fue deteriorando, agregándose otro tipo de patologías que lo llevaron a un estado de limitación importante. En pocas semanas, su estado de salud se agravó sin poder ser recuperado, falleció en la noche del día 08 de enero del presente año.

Nuestro querido Maestro, don Luis, deja en todos sus alumnos quienes lo conocimos gran sabiduría, valiosas lecciones, grandes conocimientos y recuerdos inolvidables que conservaremos el resto de nuestras vidas en gran número de alumnos que formó de Generaciones de Anestesiólogos y que nos obliga a continuar con la gran responsabilidad de seguir su ejemplo y enseñanzas para el bien de la población que amerita nuestros conocimientos.

Sea éste, un valioso y sentido reconocimiento para nuestro querido Maestro que nos ha dejado y que influyó en gran forma en nuestra preparación académica y personal para el buen desempeño de nuestras actividades personales y profesionales (Figura 1).

Descanse en Paz. Con inmensa gratitud. 